\title{
Assessment of the severity of acute pulmonary embolism using CT pulmonary angiography parameters
}

\author{
Vladimir Kincla ${ }^{\mathrm{a}}$ Vera Feitova ${ }^{\mathrm{b}}$, Roman Panovsky ${ }^{\mathrm{a}}$, Radka Stepanova ${ }^{\mathrm{c}}$
}

\begin{abstract}
Aim. To evaluate the association between computed tomography parameters and clinical signs in patients with acute pulmonary embolism.

Methods. 109 patients retrospectivelly selected from hospital database with acute pulmonary embolism verified by CT pulmonary angiography. The following parameters were assessed: pulmonary artery diameter to aorta diameter ratio $(\mathrm{PA} / \mathrm{Ao})$, normalized pulmonary artery diameter ( $\mathrm{nPA}$ ), right ventricular to left ventricular diameter ratio from CT (RV CT/LV CT), normalized end-diastolic right ventricular diameter (nRVD echo) and right to left ventricular end diastolic diameter ratio (RV echo/LV echo) from echocardiography.

Results. Multivariate regression analysis showed a significant association between PA/Ao and thrombolysed (0.99) to non-thrombolysed ( 0.90 ) patients, $\mathrm{OR}=1.56 P=0.012$, and also RV CT/LV CT and thrombolysed 1.5 to non-thrombolysed (0.94) patients $\mathrm{OR}=1.24 P=0.002$. The significant difference was also found in intensive care unit hospitalization necessity (ICU-Y/N) and RV CT/LV CT ratio (ICU-Y 1.42, ICU-N 0.91) OR=1.26 P=0.003, and RV echo/LV echo (ICU-Y 0.82, ICU-N $0.65) \mathrm{OR}=1.83 \quad P=0.033$.

Conclusion. From the CT pulmonary angiography parameters, the RV CT/LV CT showed a significant association with both thrombolysis administration and ICU hospitalization. The PA/Ao had relation only to thrombolytic therapy as well as RV echo/LV echo only to ICU hospitalization.
\end{abstract}

Key words: pulmonary embolism, risk assessment, CT angiography, clinical signs

Received: January 18, 2013; Accepted with revision: October 22, 2013; Available online: November 8, 2013 http://dx.doi.org/10.5507/bp.2013.082

${ }^{a}$ Department of Cardiovascular Diseases, International Clinical Research Center, St. Anne's University Hospital in Brno, Brno, Czech Republic
bDepartment of Imaging Methods and International Clinical Research Center, St. Anne's University Hospital in Brno, Brno
'International Clinical Research Center, St. Anne's University Hospital in Brno, Brno
Corresponding author: Vladimir Kincl, e-mail: vladimir.kincl@fnusa.cz

\section{INTRODUCTION}

Acute pulmonary embolism (PE) is one of the most frequent cardiovascular conditions. The incidence in Europe is about 50 cases/100000 inhabitants according to data from the European Society of Cardiology ${ }^{1}$. The mortality rate of acute pulmonary embolism is about $30 \%$ in non-treated patients and about $8 \%$ in treated patients. Approximately $11 \%$ of patients die of sudden death ${ }^{2}$. A number of risk factors have been identified: age over 70 years, congestive heart failure and other cardiopulmonary diseases ${ }^{3,4}$. Echocardiographic findings ${ }^{4,5}$ as right ventricular (RV) dysfunction (assessed as hypokinesis of $\mathrm{RV}$ free wall, or dilatation of right ventricle compared to left ventricle) and laboratory markers as troponin $\mathrm{T}$ (ref. ${ }^{6-8}$ ) and NT-proBNP (ref. ${ }^{9-11}$ ) are also associated with poor prognosis. One of the first examination techniques in patients with acute pulmonary embolism is CT pulmonary angiography (pCTA) and there are several studies demonstrating the importance of pCTA in patients suspected of having PE (ref. ${ }^{12}$ ). In previous studies these parameters were mainly analyzed: pulmonary artery/aorta ratio, right ventricular/left ventricular ratio, pulmonary obstruction index (POI), ventricular septal bowing (VSB) and venous contrast reflux (VCR) (ref. ${ }^{12-15}$ ). In our study, we used pulmonary artery normalized diameter (nPA), PA/Ao ratio,
RV CT/LV CT ratio in comparison with echocardiography parameters - normalized right ventricular diastolic diameter (nRV echo) and RV/LV diastolic diameter ratio (RVecho/LV echo).

\section{PATIENTS AND METHODS}

Patients hospitalized from August 2007 through May 2012 were retrospectively selected from the hospital information system. Patients with ejection fraction under $50 \%$ on echocardiography, chronic pulmonary disease in anamnesis and a recidive of PE were excluded. A total of 109 patients with pCTA confirmed pulmonary embolism were included in the study. Patients were divided according to following criteria: clinical haemodynamical signs (hypotension, defined as systolic blood pressure under $100 \mathrm{mmHg}$ or tachycardia over 100 beats per minute on admission), laboratory markers ( NT-pro BNP, troponin T), clinical outcome (thrombolysed /non-thrombolysed patients and the need for intensive care unit hospitalization).

\section{CT pulmonary angiography and echocardiography}

All patients were examined on a 64 row detector system (Lightspeed VCT, GE Healthcare, Waukesha, 


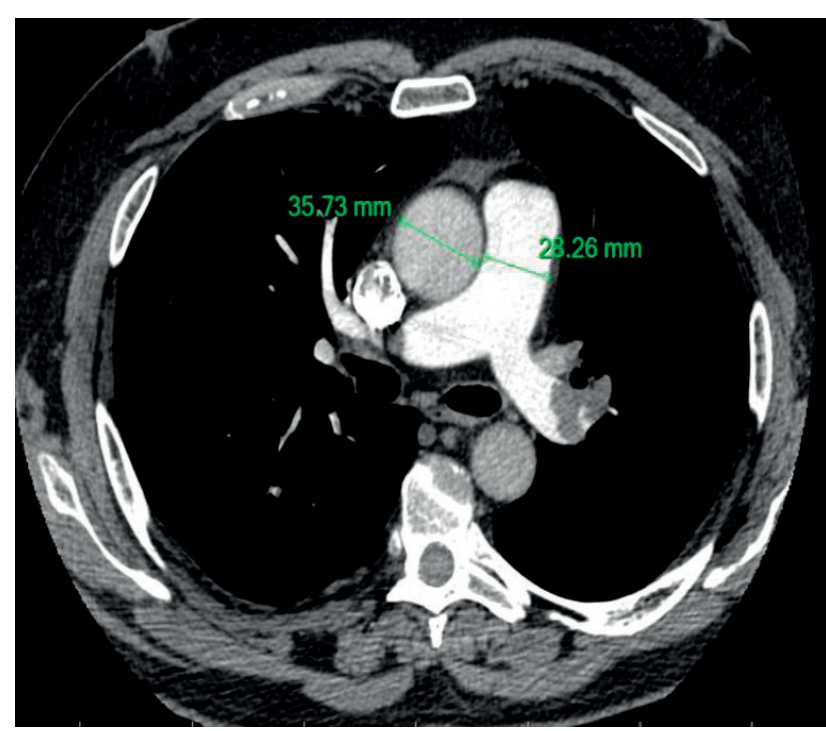

Fig. 1. Measurement of aorta and pulmonary artery diameter.

Wisconsin, USA). The examination was performed in supine position with both arms extended above the head. The following scan parameters were used: $120 \mathrm{kV}, 700$ $\mathrm{mA}$, pitch 1:0.984 and $0.625 \mathrm{~mm}$ reconstruction slice thickness. Contrast enhancement was achieved with 100 $\mathrm{mL}$ of non-ionic contrast injected at $4 \mathrm{~mL} / \mathrm{s}$. Pulmonary

Table 1a. Outcome variables.

\begin{tabular}{lc}
\hline Parameter & $\mathrm{N}(\%)$ \\
\hline Hypotension & $6(5.5 \%)$ \\
Tachycardia & $47(43.1 \%)$ \\
Hypotension and/or tachycardia & $48(44.0 \%)$ \\
Trombolysis & $32(29.4 \%)$ \\
Intensive care unit hospitalization & $59(54.1 \%)$ \\
Death & $2(1.8 \%)$ \\
\hline
\end{tabular}

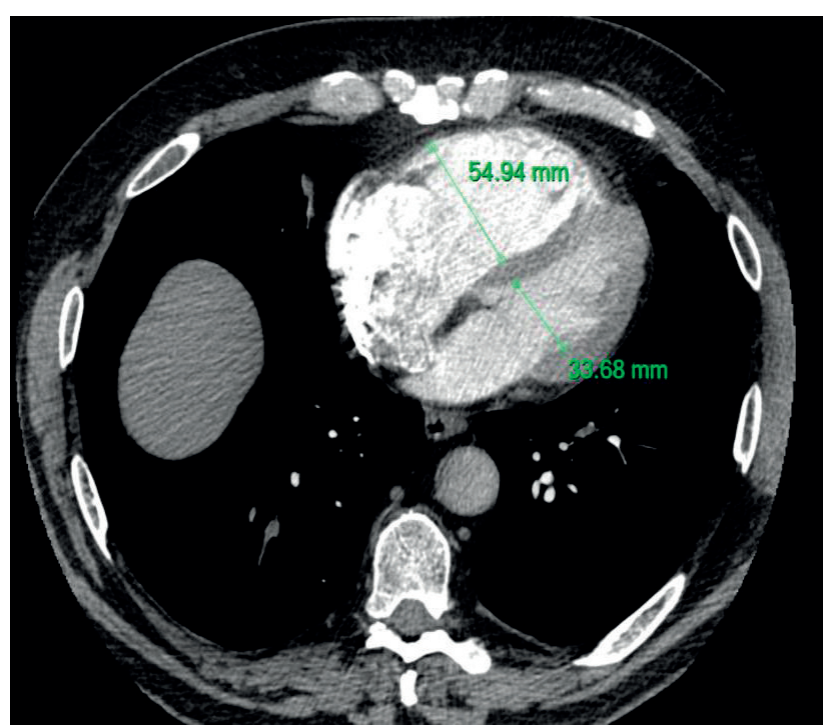

Fig. 2. Measurement of right and left ventricular diameter.

embolism was confirmed in all patients by an experienced radiologist. CT measurements were performed by a single reviewer (cardiologist), in eighteen patients the measurements were repeated by another cardiologist to assess the interobserver variability. The aortic and pulmonary artery diameter were measured at the short axis distance at the position where the pulmonary artery trunk and bifurcation were seen (Fig. 1). LV and RV diameter were measured at mitral valve plane and tricuspid valve level respectively (Fig. 2). Right and left diastolic diameter were assessed from echocardiographic measurements.

\section{Statistical analysis}

Patients were divided according to the following criteria into dichotomous groups: clinical hemodynamical signs (with hypotension and/or tachycardia on admission vs without); laboratory markers (with value of NT-pro

Table 1b. Basic characteristic of patients - continous variables.

\begin{tabular}{lccccc}
\hline & \multicolumn{5}{c}{ All patients $(\mathrm{N}=109)$} \\
\hline Parameter & N/missing & Mean (SD) & Median & $\begin{array}{c}\text { Lower quartile- } \\
\text { Upper quartile }\end{array}$ & Min-Max \\
\hline Age (years) & $109 / 0$ & $61.99(16.20)$ & 64.00 & $54.00-73.00$ & $21.0-90.0$ \\
Body mass index $\left(\mathrm{kg} / \mathrm{m}^{2}\right)$ & $109 / 0$ & $29.16(5.92)$ & 28.33 & $25.34-31.77$ & $18.0-50.8$ \\
BSA $\left(\mathrm{m}^{2}\right)$ & $109 / 0$ & $2.05(0.82)$ & 1.97 & $1.81-2.10$ & $1.5-10.2$ \\
Hospitalization (days) & $98 / 11$ & $10.91(14.24)$ & 8.00 & $7.00-11.00$ & $2.0-120.0$ \\
Intensive care unit hospitalization & $109 / 0$ & $2.90(6.35)$ & 2.00 & $0.00-4.00$ & $0.0-60.0$ \\
(days) & $43 / 66$ & $4016.55(5351.58)$ & 2352.00 & $493.00-4483.00$ & $32.0-22553.0$ \\
NT proBNP (ng/L) & $47 / 62$ & $0.07(0.14)$ & 0.03 & $0.01-0.10$ & $0.0-1.0$ \\
Troponin T (ng/L) & $109 / 0$ & $0.94(0.16)$ & 0.94 & $0.83-1.03$ & $0.6-1.5$ \\
PA/Ao & $109 / 0$ & $14.97(2.57)$ & 14.80 & $13.00-16.30$ & $10.2-22.8$ \\
nPA & $109 / 0$ & $1.25(0.49)$ & 1.14 & $0.89-1.50$ & $0.5-2.9$ \\
RV CT/LV CT & $109 / 0$ & $16.77(3.30)$ & 16.02 & $14.71-18.42$ & $10.7-27.3$ \\
nRV echo & $109 / 0$ & $0.77(0.23)$ & 0.73 & $0.61-0.87$ & $0.4-1.8$ \\
RV echo/LV echo & $83 / 26$ & $41.25(15.89)$ & 40.00 & $30.00-50.00$ & $20.0-100.0$ \\
SBP in RV (estimate) & & & &
\end{tabular}

PA - pulmonary artery, Ao - aorta, BSA - body surface area, RV - right ventricle, LV - left ventricle, SBP - systolic blood pressure, NT-pro BNP - N-terminal pro-B-type natriuretic peptide 
Table 2. Patients with and without clinical haemodynamical signs in admission.

\begin{tabular}{|c|c|c|c|c|c|c|c|}
\hline \multirow[b]{2}{*}{ Parameter } & \multirow{2}{*}{$\begin{array}{c}\text { Patients with } \\
\text { hypotension } \\
\text { and/or tachycardia } \\
(\mathrm{N}=48)\end{array}$} & \multirow{2}{*}{$\begin{array}{l}\text { Patients without } \\
\text { hypotension } \\
\text { and tachycardia } \\
\quad(\mathrm{N}=61)\end{array}$} & \multirow{2}{*}{$P^{*}$} & \multicolumn{2}{|c|}{$\begin{array}{l}\text { Univariate logistic } \\
\text { regression }\end{array}$} & \multicolumn{2}{|c|}{$\begin{array}{l}\text { Multivariate logistic } \\
\text { regression }\end{array}$} \\
\hline & & & & $P$ & $\begin{array}{c}\text { Odds ratio } \\
\text { (95\% confidence } \\
\text { interval })^{* *}\end{array}$ & $P$ & $\begin{array}{c}\text { Odds ratio } \\
\text { (95\% confidence } \\
\text { interval })^{* *}\end{array}$ \\
\hline PA/Ao & $0.96(0.87-1.03)$ & $0.91(0.82-1.03)$ & 0.163 & 0.154 & $1.20(0.94-1.53)$ & 0.501 & $1.11(0.82-1.51)$ \\
\hline nPA & $15.25(13.70-16.65)$ & $14.40(12.70-16.00)$ & 0.150 & 0.100 & $1.14(0.98-1.32)$ & 0.872 & $0.98(0.80-1.21)$ \\
\hline RV CT/LV CT & $1.41(0.99-1.75)$ & $0.94(0.82-1.23)$ & $<.001$ & $<.001$ & $1.20(1.09-1.33)$ & 0.129 & $1.10(0.97-1.24)$ \\
\hline nRV echo & $17.93(15.53-19.83)$ & $15.57(14.21-17.00)$ & $<.001$ & 0.001 & $1.26(1.10-1.45)$ & 0.644 & $0.94(0.71-1.23)$ \\
\hline RV echo/LV echo & $0.86(0.75-1.00)$ & $0.67(0.59-0.75)$ & $<.001$ & $<.001$ & $1.65(1.27-2.13)$ & 0.062 & $1.56(0.98-2.49)$ \\
\hline
\end{tabular}

PA - pulmonary artery, Ao - aorta, BSA - body surface area, RV - right ventricle, LV - left ventricle

Median (lower quartile-upper quartile) are presented.

* Wilcoxon two sample test for comparison of differences between groups of patients

** $P$-value of Wald test and odds ratio for patients with hypotension and/or tachycardia

For the parameters $P A / A o, R V C T / L V C T$ and $R V$ echo/LV echo unit 0.1 was used in order to present odds for hypotension and/or tachycardia if the value of parameters is increased by 0.1 . For parameters $P A / B S A$ and $R V$ echo index unit 1 was used.

Table 3. Patients thrombolysed or non-thrombolysed.

\begin{tabular}{|c|c|c|c|c|c|c|c|}
\hline \multirow[b]{2}{*}{ Parameter } & \multirow{2}{*}{$\begin{array}{l}\text { Trombolyzed } \\
\text { patients } \\
(\mathrm{N}=32)\end{array}$} & \multirow{2}{*}{$\begin{array}{l}\text { Non-trombolyzed } \\
\text { patients } \\
(\mathrm{N}=77)\end{array}$} & \multirow[b]{2}{*}{$P^{*}$} & \multicolumn{2}{|c|}{$\begin{array}{l}\text { Univariate logistic } \\
\text { regression }\end{array}$} & \multicolumn{2}{|c|}{$\begin{array}{l}\text { Multivariate logistic } \\
\text { regression }\end{array}$} \\
\hline & & & & $P$ & $\begin{array}{c}\text { Odds ratio } \\
\text { (95\% confidence } \\
\text { interval)** }\end{array}$ & $P$ & $\begin{array}{c}\text { Odds ratio } \\
\text { (95\% confidence } \\
\text { interval })^{* *}\end{array}$ \\
\hline PA/Ao & $0.99 \quad(0.91-1.10)$ & $0.90 \quad(0.81-1.00)$ & 0.005 & 0.004 & $1.51(1.14-2.01)$ & 0.012 & $1.56(1.10-2.21)$ \\
\hline $\mathrm{nPA}$ & $15.60(13.80-16.95)$ & $14.50(12.50-16.00)$ & 0.049 & 0.098 & $1.15(0.97-1.35)$ & 0.283 & $0.88(0.69-1.12)$ \\
\hline RV CT/LV CT & $1.50 \quad(1.28-1.79)$ & $0.94 \quad(0.82-1.27)$ & $<.001$ & $<.001$ & $1.26(1.13-1.41)$ & 0.002 & $1.24(1.08-1.43)$ \\
\hline nRV echo & $18.38(16.04-20.20)$ & $15.68(14.35-17.76)$ & $<.001$ & 0.003 & $1.23(1.07-1.40)$ & 0.360 & $1.16(0.84-1.60)$ \\
\hline RV echo/LV echo & $0.84 \quad(0.76-1.00)$ & $0.68 \quad(0.60-0.81)$ & $<.001$ & 0.006 & $1.35(1.09-1.66)$ & 0.559 & $0.88(0.58-1.34)$ \\
\hline
\end{tabular}

PA - pulmonary artery, Ao - aorta, BSA - body surface area, RV - right ventricle, LV - left ventricle

Median (lower quartile-upper quartile) are presented.

* Wilcoxon two sample test for comparison of differences between groups of patients

** $P$-value of Wald test and odds ratio for trombolyzed patients

For the parameters $P A / A o, R V C T / L V C T$ and $R V$ echo/LV echo unit 0.1 was used in order to present odds for trombolyzed patients if the value of parameters is increased by 0.1 . For parameters $P A / B S A$ and $R V$ echo index unit 1 was used.

$\mathrm{BNP}>1000 \mathrm{ng} / \mathrm{L}$ vs $\leq 1000 \mathrm{ng} / \mathrm{L}$; with value of troponin $\mathrm{T}>0.09 \mu \mathrm{g} / \mathrm{L}$ vs $\leq 0.09 \mu \mathrm{g} / \mathrm{L}$ ); clinical outcome (thrombolyzed vs non-thrombolyzed patients; needing intensive care unit hospitalization vs without; intensive care unit hospitalization $\geq 4$ days vs $<4$ days). Because the assumption of normal distribution was remarkably violated for most continuous parameters (Shapiro-Wilk's test), median, lower quartile (Q1) and upper quartile (Q3) were used for the presentation of data and non-parametric Mann-Whitney tests were conducted for the comparison of groups. Univariate and multivariate logistic regression were used to determine predictors and independent predictors of each criterion, where p-values are presented together with the Odds Ratios (OR) and their 95\% confidence intervals. Various multivariate models were used to explore the predictive power of the tested parameters. Age, sex and BMI were used to adjust the results but this did not improve the models presented. Results with $P$-value $<0.05$ are considered statistically significant.

\section{RESULTS}

A total of 109 patients were included. Fifty-one patients $(47 \%)$ were male. Mean age was 62 years (21-90 years). Fifty-nine patients (54\%) were hospitalized in the intensive care unit, 32 patients $(29 \%)$ received thrombolytic therapy. Two patients died during hospitalization and 48 (44\%) had signs of altered haemodynamics (hypotension or tachycardia) on admission. Tables 1a and 1b display findings from CT pulmonary angiography, echocardiography and laboratory measurements as well as basic patients characteristics.

\section{Haemodynamical signs on admission}

Table 2 shows the association of CT and echocardiography parameters with hypotension and/or tachycardia as presenting on admission. In univariate logistic regression analysis, the RV CT/RV CT, nRVD echo and RVD echo/ LVD echo showed significant association with haemody- 

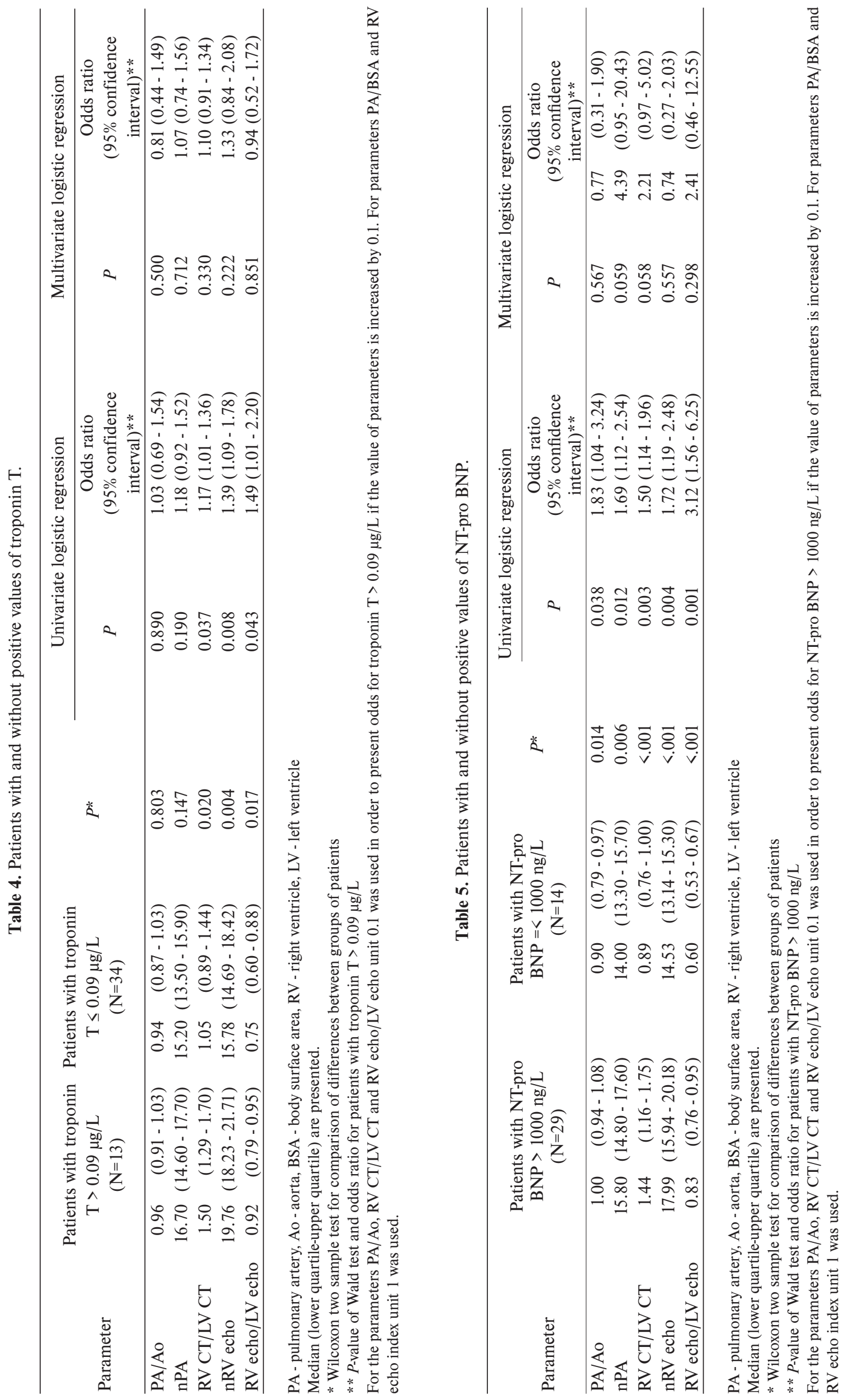
namical signs, whereas in multivariate logistic regression none of the parameters were significant.

\section{Therapy with fibrinolytics}

The use of systemic thrombolysis from the univariate logistic regression was significantly related to PA/Ao ratio, RV CT/LV CT, nRV echo and RV echo/LV echo. Only $\mathrm{PA} /$ Ao ratio, RV CT/LV CT were confirmed as independent predictors from the multivariate analysis (Table 3).

\section{Increased troponin $\mathrm{T}$ and NT-proBNP levels}

Troponin-T above $0.09 \mu \mathrm{g} / \mathrm{L}$ from the univariate logistic regression was significantly associated with RV CT/ LV CT, normalized RV diastolic diameter and RV/LV diastolic diameter ratio. For NT-proBNP, all CT and echo parameters presented significant association in univariate analysis. None of the parameters were significant from the multivariate analysis for troponin T or for NT-proBNP (Table 4 and 5).

\section{Necessity for ICU treatment}

Table 6 displays the association of examined parameters and necessity for ICU hospitalization. The univariate analysis showed statistically significant results for nPAD, RV CT/LV CT, nRVD echo and RV echo/LV echo. In the multivariate analysis, only RV CT/LV CT and RV echo/ $\mathrm{LV}$ echo were determined as independent predictors.

The mean intraobserver relative changes of measurements were $1.94 \%$ for Ao diameter, $0.03 \%$ for PA diameter, $4.58 \%$ for RV CT and $1.58 \%$ for LV CT. Interobserver measurements showed following variations: Ao $3.74 \%$, PA $1.67 \%$, RV CT $4.8 \%$ and LV CT $3.86 \%$.

\section{DISCUSSION}

Multidetector CT pulmonary angiography is currently probably the most frequently used imaging technique for the diagnostics of acute pulmonary embolism ${ }^{15,16}$. The assessment of severity of pulmonary embolism by CT pulmonary angiography has been studied for several years, and scores for pulmonary vessel obstruction have been developed ${ }^{17,18}$. Some studies found a significant relation between pulmonary clot score and mortality ${ }^{19,20}$ but the others did not ${ }^{15,18,21}$. These findings suggest that not only pulmonary obstruction score but mainly subsequent right ventricular dysfunction determines the clinical outcome in patients with acute pulmonary embolism. Obstruction of pulmonary vessels more than $30 \%$ leads to acute pulmonary hypertension and sudden increase in right ventricular afterload. This may cause RV dilatation, hypokinesis and progression to RV failure. In severe cases, low right ventricular output results in systemic hypotension and circulation collapse ${ }^{22}$. In our study, we found a significant association of pulmonary artery to aorta ratio and right to left ventricular diameter ratio measured from CT images with using thrombolysis. The RV CT/LV CT and right to left diastolic diameter ratio (obtained from echocardiography) were also related to need for intensive care unit hospitalization. However, in multivariate analysis neither 
echocardiography nor CT parameters showed significant association with hypotension and/or tachycardia or blood biomarker levels. Heyer et al. ${ }^{15}$ found that acute pulmonary embolism can lead to increase in the RV CT/LV CT ratio. In a sample of 152 patients they measured a wide range 0.5 to 3.1 and the $\mathrm{RV} \mathrm{CT/LV} \mathrm{CT} \mathrm{ratio} \mathrm{was} \mathrm{also}$ the only parameter to show a significant correlation with mortality in multivariate regression analysis. This is in accordance with our results (range of RV CT/LV CT was 0.5 to 2.9), but due to the small number of dead patients, it was not possible to statistically assess this. Probably it is caused by the fact that, most patients who died of acute pulmonary embolism were in poor clinical condition and died before the CT exam was done. This is the reason why we used the necessity for thrombolysis as one of the main clinical outcomes. On the other hand, some studies found no significant association between RV CT/LV CT ratio $^{23}$, or showed that the result depends on technique used-transverse versus four-chamber sections ${ }^{24}$. The PA/ Ao ratio showed a significant association with the administration of thrombolysis in our study. This result remains controversial, because Heyer et al. ${ }^{15}$ and van den Meer et al. ${ }^{20}$ found no significant relation of this parameter to clinical conditions. In our study,we also tried to use pulmonary artery diameter normalized on body surface area, but there were no significant results from the multivariate analysis. The echocardiographic signs of right ventricular dysfunction as ventricular septal bowing (VSB) can also be assessed on CT, but in pulmonary CT angiography is VSB often overestimated due to mistake for septal flattening ${ }^{15}$. This can be improved using three-dimensional reconstructed images and ECG-triggering of scan acqusition to reduce motion artifacts. On the other hand, it leads to higher radiation dose and is time consuming. Our study has several limitations. First, it is a retrospective analysis, so the data are often incomplete and can-not comprise more parameters than we analyzed. Another limitation is using axial views, which can overestimate RV diameter in comparison with the four chamber views ${ }^{25,26}$. We also could not assess VSB as this depends on the phase of the cardiac cycle and the results are unconvincing in a non ECG-gated CT. The third limitation is relatively small number of patients. Another study, particularly a prospective is needed to confirm the accuracy of CT parameters and mainly to set the cut-off values to determine high risk patients.

\section{CONCLUSION}

In conclusion, in accordance with other studies, our results showed that the $\mathrm{RV} \mathrm{CT/LV} \mathrm{CT} \mathrm{ratio,} \mathrm{in} \mathrm{particular,}$ is significantly associated with clinical outcome - thrombolysis and ICU hospitalization necessity. It is a fast and promising parameter for risk assessment in patients with acute pulmonary embolism.

\section{ACKNOWLEDGEMENT}

This study was supported by a European Regional Development Fund - Project FNUSA-ICRC (No. CZ.1.05/1.1.00/02.0123).

Author contributions: VK: study design,literature search, data collection, measurement of parameters, figures; RP: echocardiography examinations, measurement of parameters; VF: computed tomography examinations; RŠ: statistical analysis.

Conflict of interest statement: None declared.

\section{REFERENCES}

1. Torbicki A, Perrier A, Konstantinides S, Agnelli G, Galiè N, Pruszczyk P, Bengel F, Brady AJ, Ferreira D, Janssens U, Klepetko W, Mayer E, Remy-Jardin M, Bassand JP. Guidelines on the diagnosis and management of acute pulmonary embolism. Eur Heart J 2008:29;2276315.

2. Widimský J., Malý J., Eliáš P., Lang O., Franc P., Roztočil K. Guidelines of diagnostics,therapy and prevention of pulmonary embolism Cor Vasa 2008; 50(Suppl): 1S25-1S72 (In Czech)

3. Kucher N, Walpoth N, Wustmann K, Noveanu M, Gertsch M. QR in V1-an ECG sign associated with right ventricular strain and adverse clinical outcome in pulmonary embolism. Eur Heart J 2003;24:11139.

4. Goldhaber SZ, Visani L, De Rosa M. Acute pulmonary embolism: clinical outcomes in the International Cooperative Pulmonary Embolism Registry (ICOPER). Lancet 1999;353:1386-9.

5. Kucher N, Rossi E, De Rosa M, Goldhaber SZ. Prognostic role of echocardiography among patients with acute pulmonary embolism and a systolic arterial pressure of $90 \mathrm{~mm} \mathrm{Hg}$ or higher. Arch Intern Med 2005; 165:1777-81.

6. Giannitsis E, Müller-Bardorff M, Kurowski V, Weidtmann B, Wiegand $\mathrm{U}$, Kampmann M, Katus HA. Independent prognostic value of cardiac troponin in patients with confirmed pulmonary embolism. Circulation 2000;1023:211-7.

7. Janata K, Holzer M, Laggner AN, Müllner M. Cardiac troponin T in the severity assessment of patients with pulmonary embolism: cohort study. Br Med J 2003;326:312-3.

8. Pruszczyk P, Bochowicz A, Torbicki A, Szulc M, Kurzyna M, Fijałkowska A, Kuch-Wocial A. Cardiac troponin T monitoring identifies high-risk group of normotensive patients with acute pulmonary embolism. Chest 2003;123:1947-52.

9. Krüger S, Graf J, Merx MW, Koch KC, Kunz D, Hanrath P, Janssens U. Brain natriuretic peptide predicts right heart failure in patients with acute pulmonary embolism. Am Heart J 2004;147:60-5.

10. ten Wolde M, Tulevski II, Mulder JW, Söhne M, Boomsma F, Mulder BJ, Büller HR. Brain natriuretic peptide as a predictor of adverse outcome in patients with pulmonary embolism. Circulation 2003;107:2082-4.

11. Kucher N, Printzen G, Doernhoefer T, Windecker S, Meier B, Hess OM.Low Pro-Brain Natriuretic Peptide level predict benign clinical outcome in acute pulmonary embolism. Circulation 2003;107:15768.

12. Ghaye B, Remy J, Remy-Jardin M. Non-traumatic thoracic emergencies: CT diagnosis of acute pulmonary embolism: the first 10 years. Eur Radiol 2002;12:1886-905.

13. Wood KE. Major pulmonary embolism: review of a pathophysiologic approach to the golden hour of hemodynamically significant pulmonary embolism. Chest 2002;121:877-905.

14. Staskiewicz G, Czekajska-Chehab E, Prezegalinski J, Tomaszewski A, Torres K, Torres A, Trojanowska A, Maciejewski R, Drop A. Widening of coronary sinus in $\mathrm{CT}$ pulmonary angiography indicates right ventricular dysfunction in patients with acute pulmonary embolism. Eur Radiol 2010;20:1615-20.

15. Heyer CM, Lemburg SP, Knopp H, Holland-Letz T, Nicolas V, Roggenland D. Multidetector-CT angiography in pulmonary em- 
bolism-can image parameters predict clinical outcome? Eur Radiol 2011;21:1928-37.

16. Bozlar U, Gaughen JR, Nambiar AP, Hagspiel KD. Imaging diagnosis of acute pulmonary embolism. Expert Rev Cardiovasc Ther 2007;5:51929

17. Mastora I, Remy-Jardin M, Masson P, Galland E, Delannoy V, Bauchart $J$ J, Remy J. Severity of acute pulmonary embolism: evaluation of a new spiral CT angiographic score in correlation with echocardiographic data. Eur Radiol 2003;13:29-35.

18. Qanadli SD, El Hajjam M Vieillard-Baron A, Joseph T, Mesurolle B, Oliva VL, Barre O, Bruckert F, Dubourg O, Lacombe P. New CT index to quantify arterial obstruction in pulmonary embolism: comparison with angiographic index and echocardiography. Am J Roentgenol 2001;176:1415-20.

19. Wu AS, Pezzullo JA, Cronan JJ, Hou DD, Mayo-Smith WW. CT pulmonary angiography: quantification of pulmonary embolus as a predictor of patient outcome-initial experience. Radiology 2004;230:831-5.

20. van der Meer RW, Pattynama PM, van Strijen MJ, van den Berg Huisman MV. Right ventricular dysfunction and pulmonary ob struction index at helical CT: prediction of clinical outcome during 3-month follow-up in patients with acute pulmonary embolism. Radiology 2005;235:798-803.
21. Collomb D, Paramelle PJ, Calaque O, Bosson JL, Vanzetto G, Barnoud D, Pison C, Coulomb M, Ferretti G. Severity assessment of acute pulmonary embolism:evaluation using helical CT. Eur Radiol 2003;13:1508-14.

22. Piazza G, Goldhaber SZ. Acute pulmonary embolism: Part I: epidemiology and diagnosis. Circulation 2006;114:e28-e32.

23. Araoz PA, Gotway MB, Harrington JR, Harmsen WS, Mandrekar JN. Pulmonary embolism:prognostic CT findings. Radiology 2007; 242:889-97.

24. Quiroz R, Kucher N, Schoepf UJ, Kipfmueller F, Solomon SD, Costello $\mathrm{P}$, Goldhaber SZ. Right ventricular enlargement on chest computed tomography: pronostic role in acute pulmonary embolism. Circulation 2004;109:2401-4.

25. Park JR, Chang SA, Jang SY, No HJ, Park SJ, Choi SH, Park SW, Kim $\mathrm{H}$, Choe YH, Lee KS, Oh JK, Kima DK. Evaluation of right ventricular dysfunction and prediction of clinical outcomes in acute pulmonary embolism by chest computed tomography:comparisons with echocardiography. Int J Cardiovasc Imaging 2012;28:979-87.

26. Kang DK, Thilo C, Schoepf UJ, Barazza JM, Nance JW, Bastarrika G, Abro JA, Ravenel JG, Costello P, Goldhaber SZ. CT signs of right ventricular dysfunction. Prognostic role in acute pulmonary embolism J Am Coll Cardiol Img 2011;4:841-9. 